\title{
Genotypic assessment of productivity and quality of berries of strawberry varieties
}

\author{
Vadim Lapshin ${ }^{1 *}$, Valentina Yakovenko ${ }^{1}$, and Sergey Shcheglov ${ }^{2}$ \\ ${ }^{1}$ Federal State Budget Scientific Institution «North Caucasian Federal Scientific Center of Horticulture, \\ Viticulture, Wine-making», 39 str. 40 Let Pobedy, Krasnodar, 350901, Russia \\ ${ }^{2}$ Federal State Budgetary Educational Institution of Higher Education «Kuban State University», 149 \\ str. Stavropol'skaya, Krasnodar, 350040, Russia
}

\begin{abstract}
The genotypical potential of strawberry varieties is the basis for the implementation of economically valuable crop indicators in specific growing conditions. Assessment of the variability of productivity traits and quality of berries is one of the key directions in many modern studies on the selection and variety study of garden strawberries. The goal of this work was to assess strawberry varieties by a complex of characteristics of the yield structure and fruit quality, taking into account their genotypic characteristics, as well as to identify of their hereditary potential in regional cultivation conditions. The analysis of long-term data on 17 varieties of strawberries has been carried out. Using the methods of two-way analysis of variance, contributions of the principal components and Ward's cluster analysis, an assessment was made of the variability of the taken into account traits in strawberry varieties. Combining the studied varieties into groups made it possible to identify the best forms by the valuable traits. A high responsiveness to the cultivation conditions in the Krasnodar region was established for the varieties Nelli, Alba, Florence, Elegia, Honeoye, Onda and Vima Xima in accordance with their genotypic potential.
\end{abstract}

\section{Introduction}

Genotypic features of strawberry varieties of various ecological and geographical origin, taking into account their diverse hereditary structure, are the main scientific and practical criterion in modern research on the variety study of strawberries [1-3].

The high level of quantitative values of economically valuable traits, taking into account the ecologically conditioned adaptability of garden strawberries, is directly related not only to the selection of varieties with the highest values of valuable traits, but also to the selection of promising genotypes according to the ratio of their hereditary potential and phenotypic manifestation of the studied indicators [4-6].

Features of the growing environment have a direct impact on the implementation of strawberry genotypes in the formation of indicators of productivity and quality of berries, due to their rate of response to the conditions of growth and development of plants [7-9].

\footnotetext{
*Corresponding author: lavai@list.ru
} 
The issues of genotypic proximity of the studied forms of strawberries, manifested in the parallelism of variability of variation arrays of traits, considered in a number of new works on breeding and genetic topics, almost always affect the description and assessment of the hereditary economically significant potential of varieties in the light of not only continuous renewal of the assortment, but also improvement cultivation technologies [10-12].

The applied genetic and statistical methods for assessing varieties by a group of traits and several independent factors are traditionally based on models of analysis of variance with the calculation of several variance variances, as well as on multivariate mathematical procedures, which include the method of principal components and cluster analysis, which involves the use of not only direct empirical values of the considered characteristics, but also quantitative indicators of variation for each of the studied forms. The integrated assessment of linear combinations of the considered traits provides for the unification of the studied objects into groups, according to the similarity of genotypically determined directions of variability [13$15]$.

Taking into account the adequate specificity of the graphic display of the formed groups of varieties according to the principle of minimum intragroup and maximum intergroup variance, the use in cluster analysis, in addition to direct quantitative indicators of traits, the values of internal variances, reflecting the reaction rate of each studied genotype to growing conditions for individual traits, seems appropriate for assessing the closeness of the phenotypic manifestation of the complex of the studied traits to the varietal characteristics of the strawberry genotypes.

The production need for the selection of varieties with high indicators of productivity, yield and quality of berries, taking into account the updated assortment in regional growing conditions, as well as increasing consumer requirements, determines the relevance of work to identify the genotypic potential of strawberry varieties and the selection of promising forms among them for a combination of economically valuable characteristics.

In our studies, the goal was to assess strawberry varieties by a complex of characteristics of the yield structure and quality of berries, taking into account their genotypic characteristics, as well as to identify the hereditary potential of the studied forms of culture in regional cultivation conditions.

\section{Materials and methods}

An assessment was made of the productivity, biological yield and quality of berries of 17 strawberry varieties: Alba, Clery, Syria, Nelli, Asia, Alina, Elegia, Roxana, Honeoye, Onda, Elsanta, Florence, Vima Xima, Bogota, Taira, Kemia, Malling Pandora.

The analysis of the dynamics and directions of variability of the studied characteristics, the identification of the best cultivars according to the general matrix of characteristics, as well as the assessment of the proximity of genotypes to phenotypic manifestations, taking into account their genetic potential, were carried out on the basis of an analysis of variance model with a description of the factors of variability and their interaction, as well as multivariate statistical procedures that included quantitative contributions of the principal components and cluster analysis according to the Ward's method. Mathematical data processing provided for a special source [16] and electronic distribution Statistica v.10.

\section{Results and discussion}

The general diversity of strawberry genotypes, taking into account the influence of the year, was assessed using a two-factor analysis of variance in the directions of variability "variety" 
and "year", as a result of which reliably significant contributions of factors and their interactions on the implementation of all considered traits were established.

The calculated indicators of criterion F for the factors "variety", "year" and interaction "variety $\times$ year" were the following values: by the number of peduncles $27.9 ; 46.1 \& 3.9$; by the number of berries $33.3 ; 53.9 \& 4.8$; by the average weight of the berry $23.1 ; 63.9 \& 6.0$; yield $42.0 ; 126.6 \& 7.7$; by density of berry pulp $63.6 ; 11.5$ and 7.8 . The standard F values for the analysis of variance factors for the $5 \%$ level of significance were significantly lower than the actual ones and amounted to $1.7 ; 3.0$ and 1.5 , respectively.

According to the studies, the genotype of the variety had the greatest impact on the traits taken into account. Genotypic variation ranged from 28.3 (average berry weight) to 55.9 (berry density) percent of total variance. The influence of the conditions of the year of cultivation ranged from 1.7 (berry density) to $19.6 \%$ (yield). The combined effect of the two factors taken into account contributed to the total variability from 12.0 (number of peduncles) to $18.7 \%$ (berry density).

The results of analysis of variance indicate both the predominant contribution of genotypes to the total phenotypic diversity of the studied varieties and their rather high responsiveness to the conditions of the year of cultivation. It also shows a sufficient level of variability of traits for further grouping of strawberry varieties and identification of their genotypic potential.

To level the dimension of the initial data while preserving the original array of information, the empirical indicators of features were converted into linear combinations using principal component analysis. The influence of linear combinations of the first 3 principal components was established, explaining $94.79 \%$ of the total variability of all considered traits and making it expedient to conduct cluster analysis according to the Ward's method using individual contributions of the principal components to each studied variety. The grouping of strawberry genotypes into cluster groups is shown in Figure 1.

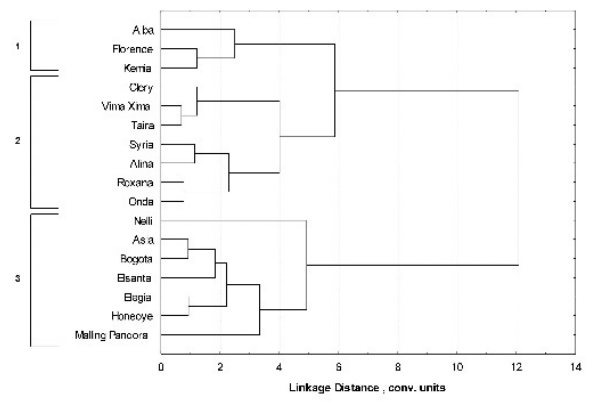

Fig. 1. Results of cluster analysis of strawberry varieties according to the values of the first three principal components

When the groups were combined with the division of the constructed dendrite by 5.5 conventional units, three clusters were obtained, the first of which included 3 , the second and third - 7 varieties, respectively.

The correctness of the cluster solution was confirmed using analysis of variance, which showed significant differences between the three obtained clusters for $5 \%$ significance. With the standard indicator of the F criterion of 3.7, the obtained values for the four studied characteristics in the groups were 5.0-20.0, which indicates that the "cluster" factor has a significant effect on all characteristics, except for the density of the pulp of the berry, for which there was calculated F 2.7. 
1st group includes varieties Alba, Florence, Kemia; 2nd - Clery, Vima Xima, Taira, Syria, Alina, Roxana, Onda; 3rd - Nelli, Asia, Bogota, Elsanta, Elegia, Honeoye, Malling Pandora. 1 .

The average values of the traits in the selected groups of varieties are presented in Table

Table 1. Average values of characteristics in clusters

\begin{tabular}{|l|c|c|c|}
\hline \multicolumn{1}{|c|}{ Признак } & \multicolumn{3}{c|}{ Clusters } \\
\cline { 2 - 4 } & 1 & 2 & 3 \\
\hline Number of peduncles, pcs / plant & 11,5 & 12,6 & 16,9 \\
\hline Number of berries, pcs / plant & 48,0 & 58,5 & 76,0 \\
\hline Average berry weight, g & 16,9 & 13,4 & 14,3 \\
\hline Yield, g / plant & 809,7 & 790,7 & 1097,7 \\
\hline Berry pulp density, g & 350,0 & 360,0 & 290,0 \\
\hline
\end{tabular}

The highest values of the characteristics of productivity and berry yield were noted in the third cluster, which, among others, included varieties Nelli, Asia and Bogota. The Nelli variety also has the highest density of berry pulp - $450 \mathrm{~g}$.

The varieties Alba, Florence and Kemia, which made up the first cluster, are distinguished by the highest values of the average berry mass - 16.1; 17.4 and $17.0 \mathrm{~g}$, respectively. Alba berries also have a high pulp density - $400 \mathrm{~g}$.

Seven varieties, combined into a second cluster, have a high overall density of pulp. The maximum values were noted for the varieties Alina, Syria and Roxana - 400, 380 and $360 \mathrm{~g}$, respectively.

The variability of the studied economically valuable traits, determined by the hereditarily determined norm of the reaction of strawberry varieties to the conditions of the year of cultivation, has its quantitative assessment not only in intervarietal differences revealed as a result of variance and cluster analysis, but in the intravarietal variance $\sigma^{2}$ for each individual quantitative trait, which is direct genotypic assessment of the response of each variety to the ecological characteristics of cultivation. The direct dependence of the intravarietal variance on the specificity of the genetic structure of the cultivar forms indicates the selection feasibility of a comparative analysis of the distribution of varieties in the corresponding groups, both in accordance with the values of the main components and with the indices of the internal genotypic variance of varieties according to the taken into account characteristics.

According to the studied characteristics, the following intravarietal variances were obtained: according to the number of peduncles - 3.47-25.29; by the number of berries $76.56-831.40$; by the average weight of the berry - 2.18-19.74; by harvest - 13254.71382628.84; by density of berry pulp - 721.94-8355.79. Taking into account the unevenness of the signed orders of the numbers obtained, the variances were converted into percentages to their maximum values for each feature, ranging from 3.5 to 76.2 conventional percentages for the entire complex of 5 studied features.

The calculated share indicators passed the cluster analysis procedure according to the Ward's method, the results of which are shown in Figure 2. 


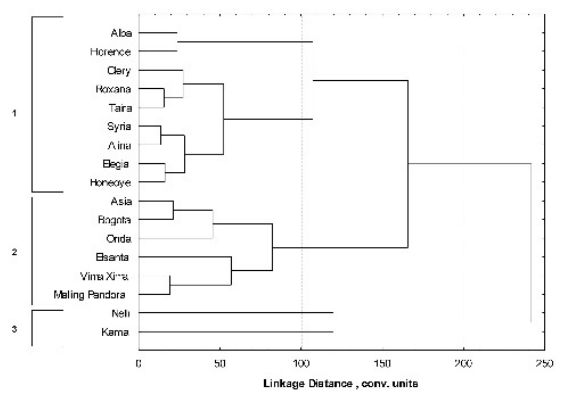

Fig. 2. Results of cluster analysis of strawberry varieties according to the values of the percentage of intravarietal variances.

The formation of groups of varieties at a conditional uniting distance of 150 revealed 3 clusters, the composition of which had both similarities and a number of differences with that when clustering according to the values of the principal components.

For the groups that are closest in their content, with both variants of cluster analysis, a comparison of the varietal composition was carried out, the results of which are presented in Table 2.

Table 2. Comparison of clusters obtained from the values of the principal components and the percentage ratios of intravarietal variances

\begin{tabular}{|l|l|}
\hline \multicolumn{1}{|c|}{ By principal components } & \multicolumn{1}{|c|}{$\begin{array}{c}\text { According to the ratios of intravarietal } \\
\text { variances }\end{array}$} \\
\hline Alba, Florence, Kemia & Nelli *, Kemia \\
\hline $\begin{array}{l}\text { Clery, Vima Xima, Taira, Syria, Alina, } \\
\text { Roxana, Onda }\end{array}$ & $\begin{array}{l}\text { Alba *, Florence *, Clery, Roxana, Taira, } \\
\text { Syria, Alina, Elegia *, Honeoye * }\end{array}$ \\
\hline $\begin{array}{l}\text { Nelli, Asia, Bogota, Elsanta, Elegia, } \\
\text { Honeoye, Malling Pandora }\end{array}$ & $\begin{array}{l}\text { Asia, Bogota, Onda *, Elsanta, Vima Xima } \\
\text { *, Malling Pandora }\end{array}$ \\
\hline
\end{tabular}

Note: * - varieties in clusters by variance that do not coincide in their position in clusters by main components.

The close relationship between the values of the contributions of the principal components and internal variances indicates a genotypically determined similarity in the directions of variability in varieties that retained their position in both variants of combining according to the set of parameters taken into account. These varieties include 10 studied: Kemia, Clery, Roxana, Taira, Syria, Alina, Asia, Bogota, Elsanta and Malling Pandora.

The study of intervarietal and internal variability of productivity and quality of berries in accordance with the variation in the values of the principal components and variance revealed a group of varieties whose genotypic potential goes beyond the variability of the considered traits in terms of the contributions of the main components, which testifies in favor of the increased responsiveness of these genotypes to growing conditions. These are Nelli, Alba, Florence, Elegia, Honeoye, Onda and Vima Xima. It seems advisable to pay particular attention to these varieties in cultivation in order to obtain high yields. 


\section{Concussion}

The assessment of the variability of strawberry genotypes based on productivity, yield and quality of berries made it possible to identify varieties that are promising for industrial cultivation in the Krasnodar region: Nelli, Asia and Bogota.

The genotypic potential exceeding the phenotypic manifestation in terms of a complex of traits in varieties Nelli, Alba, Florence, Elegia, Honeoye, Onda and Vima Xima indicates their increased responsiveness to improving growing conditions in the region.

\section{References}

1. M.T. Ariza, L. Miranda, J.A. Gómez-Mora, J.J. Medina, D. Lozano, P. Gavilán, C. Soria, Martínez-Ferri, Agron., 11, 261 (2021) https://doi.org/10.3390/agronomy11020261

2. B. Mezzetti, F. Giampieri, Y. Zhang, C.-F. Zhong, J. Berry Res., 8, 205-221 (2018) https://doi.org/10.3233/jbr-180314

3. A. Gabriel, J.T.V. Resende, A.R. Zeist, L.V. Resende, N.C.V. Resende, A.G. Galvão, R.A. Zeist, R.B. de Lima Filho, J.V.W. Corrêa, C.K. Camargo, Genet. Mol. Res., 17(3) (2018) http://dx.doi.org/10.4238/gmr18041

4. G. Temocico, M. Sturzeanu, V. Ion, S. Cristea, Rom. Biotechnol. Lett., 24(4), 742-748 (2019) https://doi.org/10.25083/rbl/24.4/742.748

5. B. Mezzetti, F. Balducci, F. Capocasa, C.-F. Zhong, R. Cappelletti, L. Di Vittori, L. Mazzoni, F. Giampieri, M. Battino, Int. J. Fruit Sci., 16(1), 194-206 (2016) http://dx.doi.org/10.1080/15538362.2016.1250695

6. A. Sønsteby, U.M. Roos, O.M. Heide, Acta Agric. Scand. B Soil Plant Sci., 67(3), 278283 (2017) http://dx.doi.org/10.1080/09064710.2016.1261933

7. E. Krüger, M. Josuttis, R. Nestby, T.B. Toldam-Andersen, C. Carlen, B. Mezzetti, J. Berry Res., 2(3), 143-157 (2012) http://doi.org/10.3233/JBR-2012-036

8. C. Cocco, S. Magnani, M.L. Maltoni, I. Quacquarelli, M. Cacchi, L.E.C. Antunes, L.F. D'Antuono, W. Faedi, G. Baruzzi, J. Berry Res., 5, 145-155 (2015) https://doi.org/10.3233/JBR-150098

9. M.M. Mathey, S. Mookerjee, L.L. Mahoney, K. Gündüz, U. Rosyara, J.F. Hancock, Ph.J. Stewart, V.M. Whitaker, N.V. Bassil, T.M. Davis, Ch.E. Finn, Euphytica, 213, 112 (2017) https://doi.org/10.1007/s10681-017-1892-6

10. S.D. Vieira, A.L.R. Araujo, D.C. Souza, L.V. Resende, M.E. Leite, J.T.V. Resende, J. Agric. Sci., 11(4), 457-469 (2019) https://doi.org/10.5539/jas.v11n4p457

11. P.K. Mishra, R.B. Ram, N. Kumar, Turk. J. Agric. For., 39, 451-458 (2015) https://doi.org/10.3906/tar-1408-99

12. G. Singh, D.S. Kachwaya, R. Kumar, G. Vikas, L. Singh, El. J. Plant Breed., 9 (1), 169182 (2018) http://doi.org/10.5958/0975-928X.2018.00021.2

13. J.L.T. Chiomento, E.P.L. Júnior, M. D’Agostini, F.S. De Nardi, T. dos S. Trentin, A.G. Dornelles, J. Huzar-Novakowiski, E.O. Calvete, Sci. Hortic., 279, 1-8 (2021) https://doi.org/10.1016/j.scienta.2020.109738

14. Sieczko, A. Masny, K. Pruski, E. Żurawicz, W. Mądry, Hort. Sci., 42(2), 83-93 (2015) http://doi.org/10.17221/123/2014-HORTSCI

15. E. Barth, J.T.V. de Resende, A.F.P. Moreira, K.H. Mariguele, A.R. Zeist, M.B. Silva, G.C.G. Stulzer, J.G.M. Mafra, L.S.A. Gonçalves, S.R. Roberto, K. Youssef, Agron., 10(4), 598 (2020) http://doi.org/10.3390/agronomy10040598

16. C.D. Cruz, Acta Sci. Agron., 35(3), 271-276 http://dx.doi.org/10.4025/actasciagron.v35i3.21251 